\title{
Some Questions
}

One of the proposals of the Activities Committee on New Directions for ALA (ACONDA) offers the possibility that the Association might become "a federation of organizations with specialized interests" under the umbrella of ALA offices responsible for general concerns and centralized services. In substance it is a proposal which has appeared in earlier Activities Committee reports, but ACONDA presents it in conjunction with another for a functional organization in which present divisional specializations might be supplanted.

ACRL has strongly endorsed the federation plan, saying that:

Academic libraries, as well as other types of libraries, are institutions having a configuration of problems which make them unique institutions in terms of priorities, personnel, and professional aims. Failure to recognize this principle and gear the reorganization of ALA to respond to this particular set of requirements would produce general mediocrity throughout the work of the Association.

Perhaps fortunately the plan is identified as a long-range option, and ACONDA recommends "extensive study by staff and membership to develop creative schemes for restructure of the Association."

Creative schemes are needed, certainly, to make the Association effective, on the one hand, and representative on the other.

John Lorenz wrote to ACONDA (Final Report, p. 82):

ALA has become a large organization. In the process it has become too unwieldy, expensive and, in many cases fruitless to have hundreds of committees and hundreds of meetings, the principal or only result of which is membership involvement or communication. These are no longer sufficient justification. The Executive Board and the Divisions should be seriously asked to reexamine the need for all committees and consider the alternative, where necessary or desirable, of having a responsible individual (possibly a member of an existing board) to be responsible for action and/or communication as needed in particular areas of concern.

Could ACRL, as a semiautonomous association, continue to contribute to the general welfare of the profession as well as to the advancement of academic librarianship?

Can ACRL set an example for the other federated associations in 
reducing the size and complexity of ALA in the manner which $\mathrm{Mr}$. Lorenz suggests? Three current measures of the magnitude of this problem, of course, are the thousand meetings of the annual conference, the increase in dues, and the decrease in membership. Only a third of the librarians in the U.S. belong to their national professional society.

Can ACRL find means for controlling the proliferation of sections, committees, and subcommittees with overlapping interests? Can ACRL control the Standing Committee Syndrome, which rewards the assiduous committeeman with brownie points, travel money, and selective friendship for finding means of keeping a good thing going?

The recent decline in membership confirms the need for New Directions, and federation, on the face of it, would be less of an innovation than would be the alternative scheme of functional organization. Nevertheless ACRL has contributed substantially over the years to the membership-and the leadership-of ALA, and it can be expected to continue this role in solving ALA's urgent and perplexing organizational problems.

David W. Heron 